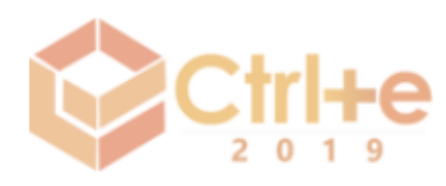

\title{
Desafios da Gestão de uma Creche no Uso Pedagógico das TDIC e Alinhamento com a BNCC
}

\author{
${ }^{1}$ Amanda Caroline Marques da Cunha, ${ }^{1}$ Flávia Luiza de Lira
}

${ }^{1}$ Programa de Pós Graduação em Educação Matemática e Tecnológica - EDUMATEC Universidade Federal de Pernambuco (UFPE) Caixa Postal 7851. 50732-970 Recife, PE - Brasil

amandaline.f@gmail.com, prof.flavialuiza@gmail.com

\begin{abstract}
The study aims to analyze the strategies and proposals for teacher education adopted by the management of a day care center, in view of the pedagogical use of ICT in order to meet what is proposed in the BNCC. The methodological course has a qualitative character, where we use some of elements of discourse analysis. For this we conducted an interview, in which we analyzed in the discourse of professionals the level of knowledge of their duties and alignment with the BNCC. The results reveal an active management body that seeks to meet the wishes of the school community in the construction and conduct of the PPP, but there is a gap in the development of strategies and articulation with the teachers.
\end{abstract}

Resumo. $O$ estudo tem por objetivo analisar as estratégias e propostas de formação docente adotadas pela gestão de uma creche, frente ao uso pedagógico das TDIC de modo a atender o que está proposto na BNCC. O percurso metodológico possui um caráter qualitativo, onde nos utilizamos de alguns de elementos da análise de discurso. Para isto realizamos uma entrevista, na qual analisamos no discurso das profissionais o nível de conhecimento das suas atribuições e o alinhamento com a BNCC. Os resultados revelam um corpo gestor atuante, que busca atender os anseios da comunidade escolar na construção e condução do PPP, porém há uma lacuna no desenvolvimento de estratégias e articulação com os docentes.

\section{Introdução}

A educação em seus diversos níveis de ensino no que corresponde a gestão, atravessou décadas livre de questionamentos sobre sua forma de funcionamento, na qual os aspectos da gestão estavam pautados na administração. $\mathrm{O}$ gestor e o coordenador eram vistos como uma autarquia. Ao passar dos anos as questões de concentração de poder nessas duas figuras foram sendo questionadas, e começou a ser pensada uma perspectiva humanista destes cargos.

As discussões a respeito da descentralização do poder começaram a ganhar força, fazendo-se necessário lançar um olhar para a gestão levando em consideração as peculiaridades correspondentes ao âmbito escolar, pois o que está em jogo é a formação cognitiva, emocional, afetiva e social dos estudantes.

Tendo em vista a importância da Educação Infantil para o desenvolvimento integral da criança, é indispensável levar em consideração no processo de ensino e 
aprendizagem o meio social no qual o educando está inserido, pois as crianças estão a todo momento propondo desafios para o contexto educacional, no qual a gestão escolar deve desenvolver estratégias de mobilização da sua equipe pedagógica para atender as demandas do novo contexto educacional.

No presente artigo objetivamos analisar as estratégias e propostas de formação docente adotadas pela gestão de uma creche situada no Recife, frente ao uso pedagógico das Tecnologias Digitais da Informação e Comunicação (TDIC) de modo a atender o que está proposto na Base Nacional Comum Curricular (BNCC) que é um documento de caráter normativo que define o conjunto orgânico e progressivo de aprendizagens lessenciais que todos os alunos devem desenvolver ao longo das etapas e modalidades da Educação Básica, bem como conhecer as dificuldades enfrentadas.

Além dessa introdução o estudo apresenta uma discussão sobre as TDIC e as atribuições do gestor e do coordenador pedagógico, em seguida discorremos sobre as contribuições da BNCC para a gestão escolar. Na sequência apresentamos nossa metodologia, os resultados da pesquisa e nossas considerações finais.

\section{As TDIC e as Atribuições do Gestor e do Coordenador Pedagógico}

Para entendermos a importância do coordenador pedagógico é de suma importância compreender as suas atribuições dentro do contexto escolar. Encontramos na literatura subsídio para uma melhor compreensão das atribuições do mesmo. Para Cunha (2006) o coordenador pedagógico é o principal mediador para que as ações de formação continuada aconteçam, tendo essas ações consequências direta na prática dos docentes.

Libâneo (2003) aponta que este profissional responde pela viabilização, integração e articulação do trabalho didático-pedagógico com foco na qualidade de ensino. Sendo assim, as atribuições do coordenador pedagógico estão diretamente relacionadas a excussão de uma prática pedagógica eficiente por parte dos docentes, com a realização de um planejamento da rotina de formação continuada significativa.

Compreendemos que são inúmeras as demandas de um coordenador pedagógico, todavia é de suma importância que o mesmo zele pela sua própria formação profissional, pois assim estará habilitado para prestar formação continuada aos docentes, bem como administrar conflitos que podem surgir no contexto escolar. Sendo indispensável a sua participação em palestras, seminários, congressos, encontros pedagógicos, capacitações, cursos e outros eventos da área educacional.

No que diz respeito à utilização das TDIC é de suma importância que o coordenador pedagógico esteja preparado para acompanhar e orientar a utilização dos mesmos de modo significativo ao processo de ensino e aprendizagem, apresentando ao seu grupo de docentes, estratégias para a utilização dos recursos tecnológicos de modo pedagógico.

Já no que corresponde a gestão, segundo Ferreira e Aguiar (2006), tal palavra vem do latim gestãoônis, que significa ato de gerir, gerenciar, administrar. Portanto gestão é administração, é tomada de decisão, é organização, é direção.

Na perspectiva da gestão democrática, gerir é uma atividade coletiva que tem o seu ponto de partida no contexto sócio histórico e cultural que a instituição está inserida

$1 \mathrm{O}$ presente artigo é um fragmento de um Trabalho de Conclusão de Curso de Pós Graduação em Gestão e Coordenação Escolar, aprovado no dia 16 de Julho de 2019. Sob orientação do professor Bruno Marones, Mestre em Educação - UFPE. 
na qual todos decidem quais são as prioridades e quais ações faz-se necessário para alcançar os objetivos almejados. Sendo assim, quanto às atribuições do gestor escolar, cabe a este adotar uma postura democrática sabendo ouvir e gerir as demandas da sua equipe de trabalho, bem como ser o agente responsável por mudanças no ambiente escolar. Segundo Libânio:

Constituem, pois, desafios a competências de diretores, coordenadores pedagógicos e professores: saber gerir e, frequentemente conciliar interesses pessoais e coletivos, peculiares, culturais e exigências universais da convivência humana; preocupando-se com as relações humanas e com os objetivos pedagógicos e sociais a atingir, estabelecer formas participativas e a eficiência em processos administrativos. LIBÂNIO (2003, p.323).

Também se faz necessário que estes profissionais estejam conectados com as novas demandas educacionais, pois segundo Lemos (2005), as novas tecnologias da informação e comunicação nos colocam em meio a uma cultura da conexão generalizada, engendrando novas formas de mobilidade social e de apropriação do espaço urbano.

Sendo assim, é preciso entender que a educação não é uma área inerte, as transformações ocorrem à medida que nosso foco (o estudante) muda, e a forma na qual ele aprende está em constante processo de mudança, uma vez que os mesmos estão a todo tempo sendo "bombardeado" pelos meios de comunicação.

Cabendo ao gestor gerenciar o ambiente escolar com responsabilidade, motivação e buscando sempre inovar em sua gestão, objetivando engajar a sua equipe de trabalho visando a qualidade do ensino e o bem-estar de todos.

\section{Base Nacional Comum Curricular e suas Contribuições para a Gestão Escolar}

A Base Nacional Comum Curricular, possui o objetivo de promover o desenvolvimento integral dos estudantes, assegurando a todos os cidadãos brasileiros o acesso à educação de qualidade, alinhadas às demandas educacionais do século XXI. É responsável por garantir a oferta da educação infantil e do ensino fundamental a rede municipal de ensino, segundo a Lei de Diretrizes e Base da Educação (LDB), pois sua tarefa encontra-se na manutenção e no desenvolvimento das instituições educacionais.

Todas as demandas contidas nos documentos oficiais requerem da gestão escolar um alinhamento com o que está sendo pedido, exigindo dos profissionais clareza, acerca da diferença entre competência e habilidade, pois o trabalho do gestor e principalmente do coordenador pedagógico atinge diretamente o fazer docente, que consequentemente implica no processo de ensino e aprendizagem. Competência para a BNCC caracterizase pela mobilização de conhecimento, enquanto Habilidades corresponde a atitudes e valores para a resolução de problemas complexos do dia-a-dia.

No que diz respeito a Educação Infantil, vem sendo realizado um trabalho que interliga o educar e o cuidar numa perspectiva indissociável, na qual a gestão das escolas e creches das redes municipais de ensino, em seu trabalho articula a sua proposta pedagógica com o objetivo de expandir os conhecimentos e as habilidades das crianças, por meio da garantia de seis direitos de aprendizagem e desenvolvimento. De acordo com a BNCC (2018), tais direitos se concretizam nas seguintes ações - conviver, brincar, participar, explorar, expressar-se e conhecer-se, tendo por objetivo a educação integral das crianças. 
Na Educação Infantil, as aprendizagens essenciais compreendem tanto comportamentos, habilidades e conhecimentos quanto vivências que promovem aprendizagem e desenvolvimento nos diversos campos de experiências, sempre tomando as interações e a brincadeira como eixos estruturantes. Essas aprendizagens, portanto, constituem-se como objetivos de aprendizagem e desenvolvimento. (BRASIL, 2018, p. 44).

Dentro da proposta da Base Nacional Comum Curricular, podemos notar o deslocamento do papel da criança e do professor, pois a Base propõe que o estudante seja retirado do papel de receptor passivo do conhecimento, colocando-o como protagonista da sua aprendizagem, e retirando o professor do local de detentor do conhecimento pondo-o como mediador/facilitador do mesmo.

Esta concepção de ensino propõe a gestão das creches e escolas, repensar o seu currículo, bem como demanda aos gestores municipais formação continuada alinhandose às perspectivas pedagógicas contidas nas dez (10) competências gerais da BNCC. Pois a mesma propõe novos desafios a comunidade escolar como por exemplo a competência cinco (5) da base que corresponde a

Compreender, utilizar e criar tecnologias digitais de informação e comunicação de forma crítica, significativa, reflexiva e ética nas diversas práticas sociais para se comunicar, acessar e disseminar informações, produzir conhecimentos, resolver problemas e exercer protagonismo e autoria na vida pessoal e coletiva (BNCC 2018).

Em suma, um dos impactos mais significativos da Base Nacional Comum Curricular está pautado na forma como a gestão municipal e das instituições de ensino irão elaborar o seu Projetos Político Pedagógico, mapear as estratégias e propostas de formação continuada dos seus docentes, de modo a atender as novas concepções de metodologias de ensino alinhadas ao uso pedagógico das TDIC em sala de aula.

Tendo em vista que toda a aprendizagem é ativa, bem como o contexto que envolve a BNCC e seus impactos, é de suma importância se repensar as metodologias de ensino para a Educação Infantil, uma vez que a aprendizagem ocorre quando há interação entre aluno e objeto de conhecimento.

Quando o aluno interage com o assunto em estudo - ouvindo, falando, perguntando, discutindo, fazendo e ensinando - sendo estimulado a construir o conhecimento ao invés de recebê-lo de forma passiva do professor. Em um ambiente de aprendizagem ativa, o professor atua como orientador, supervisor, facilitador do processo de aprendizagem, e não apenas como fonte única de informação e conhecimento. (BARBOSA; MOURA, 2013, p.55).

A literatura nos aponta uma série de caminhos que pode ser percorrido pelo corpo gestor das instituições de ensino rumo ao alinhamento com os documentos oficiais, partindo da autonomia dos sujeitos envolvidos, bem como o trabalho em equipe na qual possa ser promovido um momento de reflexão e discussão sobre o objeto em estudo.

Sabemos que muitos são os entraves da educação no que corresponde a uma perspectiva inovadora, integrando pedagogicamente as TDIC no processo de ensino e aprendizagem, por este motivo é de suma importância que a gestão e a coordenação das instituições de ensino estejam alinhadas com os documentos oficiais, com as novas demandas educacionais, e realizando continuamente formações, na busca pelo aperfeiçoamento profissional, visando nortear a educação da melhor forma possível. 
Pois temos visto na contemporaneidade, é o que Lemos (2005), chama de desencaixe, que nos permite vivenciar processos globais não enraizados na nossa tradição cultural, na qual as mídias eletrônicas criam assim processos de desterritorialização em níveis políticos, econômicos, social, cultural e subjetivo. Interferindo diretamente na formação da identidade dos sujeitos.

Tendo em vista tudo que foi discutido, acreditamos que a formação do corpo gestor das instituições de ensino, deve abranger os elementos que sugere uma ação formativa que contemple os conceitos fundamentais da BNCC. Desta forma, acreditamos que a formação impactará diretamente na prática docente, de maneira a munir o professor a potencializar a aprendizagem dos estudantes, situar sua prática na mediação e impulsionar a educação para convergir com as demandas educacionais do século XXI.

\section{Procedimento Metodológico}

O presente estudo é de caráter qualitativo e para elaboração do mesmo realizamos uma revisão na literatura sobre o tema abordado, bem como uma entrevista semiestruturada com a gestora e a coordenadora de uma creche situada na Cidade do Recife que atende 160 crianças, de zero a cinco anos de idade.

Nos aproximando de alguns elementos da Análise do Discurso, e esta informação não surge de maneira gratuita, a medida em que reconhecemos o pouco tempo de leitura sobre o assunto, e as nossas limitações conceituais, uma vez que pela primeira vez nos enveredamos por este caminho, pois entendemos que a $\mathrm{AD}$ nos permite compreender diversos elementos constitutivos da sociedade.

Para Orlandi (2010), a Análise de Discurso concebe a linguagem como mediação necessária entre o homem e a realidade natural e social. Essa mediação que é o discurso, torna possível tanto a permanência e a continuidade quanto o deslocamento e a transformação do homem e da realidade em que ele vive.

Sendo assim, a Análise de Discurso objetiva compreender como o objeto simbólico produz sentido para os indivíduos, levando em consideração as condições de produção que compreende o sujeito e a situação, em sentido expandido as condições de produção correspondem ao contexto social, histórico e ideológico no qual o sujeito está inserido. $\mathrm{O}$ discurso ao ser constituído incorpora alguns fatores, que estabelece algumas condições de produção, e um deles é conhecido como relação de sentido, onde segundo essa concepção não existe discurso que não esteja relacionado com outro, onde os sentidos são resultados de relações, no qual um discurso está interligado a outro que lhe dá apoio, bem como realiza apontamentos para dizeres futuros.

Para Orlandi (2010) todo o discurso é visto como um estado de um processo discursivo mais amplo, contínuo, não havendo começo absoluto nem ponto final para o discurso, onde um dizer tem sempre relação com outros dizeres realizados, imaginados e possíveis. Estamos vivendo em uma época de novas linguagens, no qual ao se constituir uma política pública observa-se às novas demandas sociais, que são de suma importância na constituição dos documentos oficiais, tendo em vista um ideário de sujeito globalizado, onde estratégias são traçadas para que esse sujeito atinja o que está sendo proposto e se torne usuário e multiplicador da proposta, deixando de ser assim o sujeito do ideário.

Para o desenvolvimento da pesquisa realizamos uma entrevista semiestruturada, que foram gravadas, transcritas e analisadas em seguida. As entrevistas continham quatro perguntas para a gestora e coordenadora da creche, na qual as questionamos sobre: $\mathrm{O}$ 
papel da gestão, as dificuldades encontradas, e o que elas entendem como inovação pedagógica.

A seguir procedemos com as análises das questões das entrevistas realizadas com a gestora e com a coordenadora pedagógica.

\section{Análise e Discussão}

Ao iniciarmos a entrevista questionamos a gestora e a coordenadora sobre o que elas compreendem acerca do que está a cargo das suas atribuições. Para uma melhor compreensão das respostas elaboramos o seguinte quadro.

Tabela 1.

\begin{tabular}{|l|l|}
\hline \multicolumn{1}{|c|}{ Gestora } & \multicolumn{1}{c|}{ Coordenadora } \\
\hline $\begin{array}{l}\text { No meu ponto de vista ser gestora é um } \\
\text { trabalho que exige grande dedicação, } \\
\text { habilidades, criatividade, pesquisa e e }\end{array}$ & $\begin{array}{l}\text { É a função de articuladora. Articular as } \\
\text { exigências curriculares com as diferenças } \\
\text { de expectativas das famílias e até dos } \\
\text { estudo. Uma das principais tarefas é } \\
\text { conduzir a construção coletiva do Projeto } \\
\text { profissionais de sala de aula sem perder o } \\
\text { Político Pedagógico na unidade de ensino } \\
\text { estando articulado com a BNCC, exercer } \\
\text { também influência sobre a comunidade } \\
\text { escolar, diagnosticando e resolvendo } \\
\text { problemas. }\end{array}$ \\
\hline
\end{tabular}

Podemos perceber através da fala dos sujeitos uma ligação com o que fora apresentado acerca do papel do gestor e do coordenador pedagógico, uma vez que no discurso de ambas notamos uma preocupação em estar conectadas com as demandas educacionais contemporâneas, bem como atender o que fora proposto nos documentos oficiais, se ter uma gestão democrática (colaborativa), e uma coordenação que visa estar constantemente em um movimento de articulação para atender a comunidade escolar.

Ao serem questionadas sobre as dificuldades enfrentadas no exercício da sua profissão a gestora e a coordenadora pedagógica apontaram que:

Tabela 2.

\begin{tabular}{|c|c|}
\hline Gestora & Coordenadora \\
\hline $\begin{array}{l}\text { Acompanhar a inovação pedagógica, } \\
\text { como já sou antiga na rede me sinto um } \\
\text { pouco desatualizada e perdida ao tentar } \\
\text { acompanhar o avanço tecnológico, os } \\
\text { novos recursos digitais que vão surgindo } \\
\text { e utilizar as redes sociais como ferramenta } \\
\text { para o trabalho. Para lidar com essas } \\
\text { dificuldades peço ajuda e orientação a } \\
\text { alguns funcionários. }\end{array}$ & $\begin{array}{l}\text { No dia-a-dia fazer acontecer uma rotina } \\
\text { que favoreça o bom trabalho pedagógico é } \\
\text { um desafio diário. Dar sugestões para que } \\
\text { ela aconteça é uma forma de subsidiar a } \\
\text { fim de que a rotina aconteça. Pois só uma } \\
\text { boa e planejada rotina fazem acontecer um } \\
\text { bom desempenho pedagógico. }\end{array}$ \\
\hline
\end{tabular}

Podemos perceber um distanciamento das preocupações entre gestora e a coordenadora escolar, pois enquanto uma preocupa-se em estar atualizada com relação ao uso das tecnologias (que é uma demanda social e normativa) a outra está preocupada em manter uma rotina pedagógica. 
A preocupação da gestora encontra-se dentro de um discurso global, no qual chama a atenção dos profissionais de educação para o que está sendo chamado de Cultura de Inovação, que em sentido amplo, corresponde a todas possibilidades de romper com o ensino tradicional, objetivando dar significado para o aluno acerca do que está sendo abordado, é fazer com que o estudante seja o protagonista da sua aprendizagem e o professor mediador da mesma, tal perspectiva encontra-se ancorada na Base Nacional Comum Curricular, e requer dos sujeitos envolvidos na educação aproximação com as TDIC.

Ao serem convidadas a refletir sobre a Base Nacional Comum Curricular na perspectiva da integração pedagógica das TDIC, buscamos compreender como ambas tem mobilizado a comunidade escolar na qual estão inseridas para atender a essa demanda. Obtivemos as seguintes respostas.

Tabela 3.

\begin{tabular}{|c|c|}
\hline Gestora & Coordenadora \\
\hline $\begin{array}{l}\text { Uma das estratégias utilizadas foi um } \\
\text { momento de leitura, reflexão e debate } \\
\text { acerca da Base Nacional Comum } \\
\text { Curricular que foi realizado com os } \\
\text { professores e auxiliares de } \\
\text { desenvolvimento infantil. No debate } \\
\text { foram discutidas as metas e direitos de } \\
\text { aprendizagens trazidos pela BNCC, } \\
\text { confrontando-os com a política da rede. } \\
\text { Após o estudo os docentes ficaram livres } \\
\text { para realizarem seu planejamento de } \\
\text { acordo com as novas exigências } \\
\text { curriculares, sendo responsabilidade da } \\
\text { coordenação pedagógica prestar } \\
\text { orientacão e apoio sempre que preciso. }\end{array}$ & $\begin{array}{l}\text { As diversas mídias e tecnologia estão } \\
\text { presentes cada dia mais no cotidiano dos } \\
\text { estudantes que já nascem praticamente } \\
\text { sabendo utilizá-las. O desafio é trazê-las } \\
\text { para o cotidiano escolar de uma forma } \\
\text { diferente das que elas são utilizadas nas } \\
\text { casas. É enxergar as ferramentas como um } \\
\text { auxílio na aprendizagem e não apenas uma } \\
\text { forma de diversão e passatempo. Além de } \\
\text { ser uma excelente ferramenta oferecida a } \\
\text { crianças com necessidades educacionais } \\
\text { especializada. }\end{array}$ \\
\hline
\end{tabular}

Podemos perceber através da fala dos sujeitos que a nossa pergunta foi respondida em parte, pois no nosso entendimento a coordenadora relatou os benefícios da tecnologia e os desafios, porém não explicou como tem mobilizado a sua equipe de profissionais para atender a demanda da Base junto ao uso pedagógico das tecnologias.

É necessário se ter em mente que as atribuições de um corpo gestor está para além de leituras de documentos oficiais, é necessário aprofundar o conhecimento, criar democraticamente estratégias para se pôr em prática o que está prescrito, é refletir e discutir sobre o tema abordado, é dá o suporte necessário ao docente.

A preocupação em conhecer essas demandas curriculares para século XXI é importante, porém esse conhecimento por si só não garante que os direitos de aprendizagens dos alunos elencados na BNCC como fundamentais para a formação integral do sujeito, sejam assegurados, e assim a escola deixa também de cumprir com sua função social que é assegurar aos estudantes os conhecimentos necessários para a vida em sociedade.

Com base no ideário de Schlünzen Júnior (2013) percebemos a importância da necessidade de um corpo gestor antenado com o que se está sendo posto em termos de parâmetros e diretrizes curriculares para que então o processo educativo da instituição 
seja reavaliado e reconstruído de acordo com as demandas existentes. O discurso de ambas revela a necessidade de um olhar para a reconstrução do processo educativo que deve partir desde o estabelecimento de formações continuadas para o corpo docente com o foco no uso das TDIC no processo de ensino e aprendizagem, até refletir sobre novos ambientes de aprendizagem.

Podemos perceber que tanto a gestora quanto a coordenadora possuem uma certa clareza no que diz respeito às novas discussões e exigências curriculares que trazem a integração pedagógica das Tecnologias Digitais da Informação e Comunicação como parte importante do processo de ensino e aprendizagem, todavia no que diz respeito a elaboração de estratégias metodológicas, existe uma lacuna.

Ao serem interpeladas sobre os recursos tecnológicos disponíveis na unidade de ensino na qual trabalham, se todos eles são utilizados pelos docentes e de que forma, tivemos as seguintes respostas.

Tabela 4.

\begin{tabular}{|c|c|}
\hline Gestora & Coordenadora \\
\hline $\begin{array}{l}\text { Temos diversos recursos. Dentre eles } \\
\text { estão as TVs, Rádios, notebooks e as } \\
\text { mesas interativas. Quanto ao uso não sei } \\
\text { informar se todo o corpo docente os } \\
\text { utiliza, pois é a coordenação que dá } \\
\text { orientação e suporte pedagógico. Mas } \\
\text { afirmo que todos os recursos estão } \\
\text { disponíveis para os docentes utilizarem } \\
\text { como e quando quiserem. }\end{array}$ & $\begin{array}{l}\text { Nós dispomos de alguns recursos } \\
\text { tecnológicos. Entre eles as mesas } \\
\text { interativas. Que são uma excelente } \\
\text { ferramenta inclusive de auxílio ao } \\
\text { processo de alfabetização. Trabalha o } \\
\text { desenvolvimento da oralidade e da } \\
\text { produção escrita. }\end{array}$ \\
\hline
\end{tabular}

$\mathrm{Na}$ fala de ambas percebemos o conhecimento acerca dos recursos existentes, mas não notamos em nenhum dos discursos a garantia de que esses recursos vêm sendo utilizados nas aulas, pelos professores de forma a contribuir para o processo de ensino e aprendizagem dos estudantes.

\section{Considerações Finais}

Percebemos através da fala da gestora e da coordenadora da creche uma preocupação em apropriar-se dos discursos acerca das novas demandas educacionais, na qual segundo Orlandi (2010), os sujeitos estão imersos em um padrão cultural, social, político e ideológico que passou e passa por constantes mudanças, onde os sujeitos falam a partir da sua leitura de mundo.

Todo o discurso é visto como um estado de um processo discursivo mais amplo, contínuo, não havendo começo absoluto nem ponto final, não temos a exatidão de quando se iniciou os discursos sobre o tema abordado na presente pesquisa, tão pouco sabemos quando terá fim, todavia compreendemos através da fala da gestora e da coordenadora que o ser humano está em uma busca incessante pelo novo, e que as demandas globais nos impedem de estagnar, colocando-nos constantemente em um processo de mudança, e nos fazendo entender que um discurso está sempre relacionado a outro em uma rede de interligações complexas.

No discurso do corpo gestor da creche bem como na literatura apresentada podemos realizar uma sucinta análise acerca das mudanças ocorridas no âmbito educacional, a qual nos permite ampliar o campo de visão e analisar os discursos 
veiculados acerca do processo de ensino e aprendizagem, que tem sido constantemente influenciado pelo processo intercultural advindos da difusão dos meios de comunicação, e pela incessante busca dos sujeitos ao novo, pela necessidade constante de se estar sempre em movimento, imprimindo novas demandas para o âmbito educacional exigindo dos agentes envolvidos constante formação e alinhamento com os documentos oficiais em prol da boa qualidade da educação.

O objetivo almejado para essa pesquisa foi alcançados em parte, pois, através do discurso dos sujeitos foi possível perceber a preocupação em seguir normas de acordo com a proposta curricular vigente no processo de construção coletiva do Projeto Político Pedagógico, bem como o deslocamento em busca da apropriação da utilização dos recursos tecnológicos, que ficou bem claro na fala da gestora, também podemos enxergar uma política institucional existente que tenta dialogar com o contexto educacional contemporâneo.

No que diz respeito a análise das estratégias e propostas de formação docente adotadas pelo corpo gestor da creche em relação ao uso pedagógico das TDIC alinhada a BNCC identificamos uma lacuna a ser preenchida.

Podemos notar que existe um descompasso entre o discurso da gestora e da coordenadora pedagógica da creche, todavia ambas, estão preocupadas com $\mathrm{o}$ funcionamento da instituição como um todo, e isto ficou claro quando referiram-se a importância de se exercer influência na comunidade escolar, tal perspectiva faz parte dos cargos de liderança como é o caso da gestão e coordenação pedagógica, bem como a necessidade de se ter criatividade, mobilizar conhecimento, está em constante processo de atualização e articulação com a equipe de trabalho.

A Base Nacional Comum Curricular, deve ser tida pelo corpo gestor como uma referência para a formulação do currículo e das propostas pedagógicas das instituições de ensino, pois a mesma integra a política nacional da Educação Básica e vai contribuir para o alinhamento de outras políticas e ações, referentes à formação de professores, à avaliação, à elaboração de conteúdos educacionais e aos critérios para a oferta de infraestrutura adequada para o pleno desenvolvimento da educação.

Diante desta demanda é necessário que o corpo gestor das instituições de ensino, realizam além de leitura do documento, e de deixar por conta dos docentes e elaboração de estratégias para atender às atuais demandas, torna-se de suma importância a realização de formações continuada que integre o uso pedagógico das TDIC as propostas da Base, para isto é necessário que o coordenador pedagógico esteja preparado para auxiliar a sua equipe de docentes da realização desta tarefa.

$\mathrm{O}$ caminho a ser percorrido pelo corpo gestor para atender às novas demandas educacionais não é fácil, todavia percebemos através do discurso da gestora e da coordenadora o interesse em alinhar-se a essa perspectiva global.

\section{Referências}

BRASIL. Ministério da Educação. Governo Federal. (2018). Base Nacional Comum Curricular: BNCC. Brasília, DF. Disponível em: Acesso em: 17 de maio. 2019.

BRASIL. Constituição (1988). Constituição da República Federativa do Brasil. Brasília, DF: Senado Federal.

BRASIL. Lei $n^{\circ} 13.005$, de 25 de junho de 2014. Aprova o Plano Nacional de Educação - PNE e dá outras providências. Brasília: Senado Federal, 2014. Disponível em: 
<http://www.planalto.gov.br/ccivil_03/_ato2011-2014/2014/lei/113005.htm>. Acesso em: 10 set. 2017.

BARBOSA, E. F.; MOURA, D. G. Metodologias ativas de aprendizagem na Educação Profissional e Tecnológica. B. Tec. Senac, Rio de Janeiro, v. 39, n.2, p.48-67, maio/ago. 2013.

CUNHA, R. C. O. B. Pelas telas, pelas janelas: a coordenação pedagógica e a formação de professores/as nas escolas. 2006. 288p. Tese (Doutorado em Educação) - Faculdade de Educação, Universidade Estadual de Campinas, Campinas, 2006.

FERREIRA, Nara Syria Carapeto; AGUIAR, Marcia Ângela (orgs). (2006). Gestão da Educação: Impasses, perspectivas e compromissos. $5^{\circ}$ ed. São Paulo: Cortez.

LEMOS. André. Ciberespaço e Tecnologias móveis. Processos de Territorialização e Desterritorialização na Cibercultura. UFBa. 02/12/2005. https://www.facom.ufba.br/ciberpesquisa/andrelemos/territorio

LIBÂNIO, José Carlos; OLIVEIRA, João Ferreira de; TOSCHI, Mirza Seabra. (2003). Educação escolar: políticas, estrutura e organização. São Paulo: Cortez.

ORLANDI, Eni de Lourdes Puccinelli. (2010). Análise de Discurso: Princípios \& Procedimentos. Porto Alegre.

SCHLÜNZEN JÚNIOR, Klaus. (2013). Formação docente, gestão e tecnologias: desafios para a escola-volume 4- D30-Unesp/Univesp-1 ${ }^{\text {a }}$ edição graduação em pedagogia. 